\title{
Paternal epigenetic programming: evolving metabolic disease risk
}

\author{
Suzy S J Hur1,2, Jennifer E Cropley ${ }^{1,2}$ and Catherine M Suter ${ }^{1,2}$ \\ 'Victor Chang Cardiac Research Institute, Darlinghurst, New South Wales, Australia \\ 2Faculty of Medicine, University of New South Wales, Kensington, New South Wales, Australia
}

Correspondence should be addressed to C M Suter

Email

c.suter@victorchang.edu.au

\begin{abstract}
Parental health or exposures can affect the lifetime health outcomes of offspring, independently of inherited genotypes. Such 'epigenetic' effects occur over a broad range of environmental stressors, including defects in parental metabolism. Although maternal metabolic effects are well documented, it has only recently been established that that there is also an independent paternal contribution to long-term metabolic health. Both paternal undernutrition and overnutrition can induce metabolic phenotypes in immediate offspring, and in some cases, the induced phenotype can affect multiple generations, implying inheritance of an acquired trait. The male lineage transmission of metabolic disease risk in these cases implicates a heritable factor carried by sperm. Sperm-based transmission provides a tractable system to interrogate heritable epigenetic factors influencing metabolism, and as detailed here, animal models of paternal programming have already provided some significant insights. Here, we review the evidence for paternal programming of metabolism in humans and animal models, and the available evidence on potential underlying mechanisms. Programming by paternal metabolism can be observed in multiple species across animal phyla, suggesting that this phenomenon may have a unique evolutionary significance.
\end{abstract}

\section{Introduction}

Several decades on from the pioneering work of David Barker in the 1980s and 1990s (reviewed in Hanson 2015), it is now universally accepted that the environment encountered in early life can have enduring consequences for disease risk in adulthood. Once termed the developmental origins of health and disease (DOHaD) hypothesis, the idea has grown to encompass the full gamut of parental 'programming': defined here as the phenomenon whereby parental factors other than genetic elements can determine offspring traits. The DOHaD field has grown into a major biomedical research effort with promise for advancing evidence-based preventative health strategies (reviewed in Heindel et al. 2015).
The DOHaD paradigm has traditionally focused heavily on maternal factors, as the experiences of a pregnant mother are often necessarily the experiences of her developing fetus. The maternal stressors reported to influence long-term offspring health are remarkably broad (Barouki et al. 2012), but imbalanced nutrition is by far the most intensively studied (reviewed in TarryAdkins \& Ozanne 2016). Although initial epidemiological observations precipitating the DOHaD idea were derived from studies of maternal undernutrition (Barker \& Osmond 1986, Barker et al. 1989), it is overnutrition that is most pertinent in current times. Global obesity rates have grown steadily over the last four decades, and weight increases in the reproductive ages are prominent, even in

Published by Bioscientifica Ltd 
low-middle income countries (Mamun \& Finlay 2015). In many Western countries, the rates of overweight and obesity in the reproductive age are currently as high as twothirds of the population (Flegal et al. 2010). An increasing number of children are thus being born to obese parents, and available evidence indicates that these children are programmed with an increased risk of metabolic disease.

Although the contribution of fathers to metabolic programming has until recently been largely ignored, the weight of evidence now supports an independent and nongenetic paternal influence over offspring health. Our early understanding of paternal effects was largely limited to species that display paternal care: paternal behaviors such as protection, feeding and co-residency increase offspring fitness and survival across multiple species, from beetles (Eggert et al. 1998) to baboons (Buchan et al. 2003). It is now clear however that a father's influence over offspring development and fitness can be independent of any direct interaction with offspring (Crean \& Bonduriansky 2014).

Like maternal effects, paternal programming has been observed in many species, across a range of stressors that induce a variety of offspring phenotypes (reviewed in Rando 2012). For example, in rodents, paternal alcohol consumption affects offspring litter sizes and birthweight (Abel 2004); paternal psychosocial stress reduces offspring HPA stress axis responsivity (Rodgers et al. 2013); paternal odorant-induced fear induces a fear response and neural changes in odor-naïve offspring (Dias \& Ressler 2014); paternal heroin exposure induces anxious behavior in offspring (Farah Naquiah et al. 2016) and paternal fat consumption leads to modified breast cancer risk in daughters (Fontelles et al. 2016). The catalog of paternally programmed phenotypes is fast growing, and the most numerous examples are those that involve programming of offspring metabolism. The purpose of this review is to outline the evidence for paternal programming effects, in particular, those that result in metabolic disturbance in the offspring and to evaluate the potential mechanisms that may underlie the phenomenon.

\section{Epidemiological observations implicate fathers in children's long-term metabolic health}

The first reports of paternal metabolic programming effects came from epidemiological studies, and there is by now a reasonable body of evidence in support of male line metabolic programming effects in humans. These studies have revealed the complex nature of paternal programming, highlighting deterministic factors, such as the timing of exposure and gender lineage, that produce specific responses in the progeny.

The best-known epidemiological evidence for male line metabolic effects comes from the 'Överkalix' studies, which link lifespan and disease risk to nutrition in paternal ancestors. These studies are notable not only for identifying paternal programming across multiple generations but also because the nutritional stressor was experienced well before reproductive age. Överkalix is a small, geographically isolated pastoral parish of northeast Sweden, which faced severe fluctuations in food supply during the 19th century due to inconsistent crop yields. Good historical records allowed the nutritional status of individuals living during this time to be extrapolated from records of harvest yields and grain prices. Bygren and coworkers and later Pembrey and coworkers used these records to find that the lifespans of individuals born in Överkalix between 1890 and 1920 were inversely correlated with the nutritional status of their paternal grandparents (Bygren et al. 2001, Pembrey et al. 2006). A reduced lifespan was associated with excess food supply in grandparents during their pre-teen slow growth period (SGP) (age 9-12 years), whereas, conversely, extended survival was associated with poor food availability in the grandfathers' SGP (Bygren et al. 2001, Pembrey et al. 2006). This effect was both significant and large, with the average lifespan difference between the two extremes of grandchildren being $~ 32$ years (Bygren et al. 2001). A follow-up study showed that the differences in lifespan had at least in part a cardiometabolic basis: grandpaternal overnutrition during the SGP increased diabetes-related mortality, and conversely, poor SGP nutrition protected the offspring from cardiovascular disease (Kaati et al. 2002).

Other epidemiological studies indicate that paternal metabolic health at reproductive age affects metabolic health in children. One very large study used data from more than 230,000 individuals in the UK Biobank (Tyrrell et al. 2013), finding that paternal diabetes at conception predicts the risk of diabetes in offspring, and further, that birthweight at least partly mediates this association; low birthweight is in and of itself an established predictor of type 2 diabetes in later life (Whincup et al. 2008). Studies of the Guangzhou birth cohort of China found that paternal BMI positively correlated with fetal growth in males, as well as with cortisol levels in newborns (Chen et al. 2012). A longitudinal study of BMI in a different cohort, the British Birth Cohort Study, suggests that such associations may persist: in this cohort, paternal BMI correlated with childhood BMI at age 11, and also at 45 years (Cooper et al. 2010). Another longitudinal

Published by Bioscientifica Ltd. 
study found that increased paternal body fat was a strong predictor of long-term body fat changes in prepubertal daughters, independent of maternal body fat and the girls' own energy expenditure (Figueroa-Colon et al. 2000).

Metabolic consequences may arise from factors other than nutrition: in the British ALSPAC cohort, fathers who started smoking at an early age had prepubertal sons with a higher BMI (Pembrey et al. 2006). Paternal age has been found to increase the risk of obesity in young adult sons (Eriksen et al. 2013), and, independently, to have deleterious effects on children's plasma lipid profiles, glucose homeostasis and serum Igf2 levels (Savage et al. 2014).

Although epidemiological studies have provided evidence consistent with an independent and direct paternal programming of offspring health, it is not possible in human studies to rule out the contributions of genetic variants or lifestyle and social factors or inaccuracies arising from retrospective assessments of ancestral condition or participants' self-reports (Vickers 2014). For these reasons, the most robust evidence for paternal metabolic programming comes from studies in laboratory animals, where genetic and environmental variation can be tightly controlled.

\section{Model animal systems of paternal programming of offspring metabolism}

Two high-profile reports published in 2010 brought widespread attention to the contribution of a father to his offsprings' metabolism, by assessing the intergenerational effects of dietary stress in male rodents. In the first report, a high-fat diet (HFD) was used to approximate obesity in male rats: the female offspring exhibited impaired glucose handling and insulin sensitivity and a reduction in pancreatic large islets and $\beta$-cells ( $\mathrm{Ng}$ et al. 2010). In the second report, male mice were exposed to a low-protein, high-sugar diet from weaning to sexual maturation, and their offspring exhibited a dramatic rise in hepatic expression of genes involved in lipid and cholesterol biosynthesis, along with the dysregulation of many classes of liver lipids (Carone et al. 2010).

But evidence for paternal programming of metabolism existed well before this. Probably the very earliest documentation of parental metabolic programming in animal models comes from studies of offspring of animals with chemically induced diabetes. In 1965, Okamoto reported that rats or rabbits subjected to drug-induced diabetes give rise to progeny that develop sporadic diabetes, for up to five generations after the diabetogenic drug exposure (Okamoto 1965). Ensuing studies in Sprague-Dawley rats demonstrated that males were equally as capable as females of transmitting such effects: injection of sires with a single subdiabetogenic dose of the chemical alloxan induced glucose intolerance in three succeeding generations of offspring (Spergel et al. 1971). Despite the passage of time since these observations, little is known about the precise mechanisms involved, but early speculations that the non-Mendelian pattern of transmission was unlikely to reflect a purely genetic mechanism (Goldner \& Spergel 1972) now appear prescient.

There are by now a multitude of studies showing that adult male rodents exposed to nutritional stress can program metabolic symptoms in offspring. As has been seen in maternal programming models, the opposing stressors of overnutrition and undernutrition can each produce metabolically compromised offspring. Aside from the reports already mentioned, paternal metabolic programming has been demonstrated using HFDinduced obesity (Fullston et al. 2013, Wei et al. 2014), genetic obesity (Cropley et al. 2016), caloric restriction (Anderson et al. 2006) and protein restriction (Watkins \& Sinclair 2014).

As suggested by epidemiological data, paternal programming can occur even if the nutritional stressor was encountered long before reproductive age. For example, male mice exposed to a HFD solely in utero, with a normal postnatal diet, can still program decreased insulin sensitivity in their offspring (Dunn \& Bale 2009). Similarly, undernutrition of male mice during gestation (via maternal caloric restriction) leads to low birthweight not only in those males but also in their progeny (JimenezChillaron et al. 2009). The progeny also exhibit defective glucose tolerance linked to impaired $\beta$-cell function, as well as defects in liver lipid metabolism (Martinez et al. 2014). These results imply that a memory of the nutritional insult is carried by the male until reproductive age (Fig. 1).

\section{Inheritance of paternally programmed effects}

Transmission of the memory of a prior exposure to progeny prompts the question of how long such a memory might persist: can paternal exposures affect the metabolism of grandchildren or even great-grandchildren? The Överkalix studies suggest that the effects of exposures can persist for at least two generations, and in animal models, several studies show paternal programming across multiple generations. HFD-induced obesity in

Published by Bioscientifica Ltd 


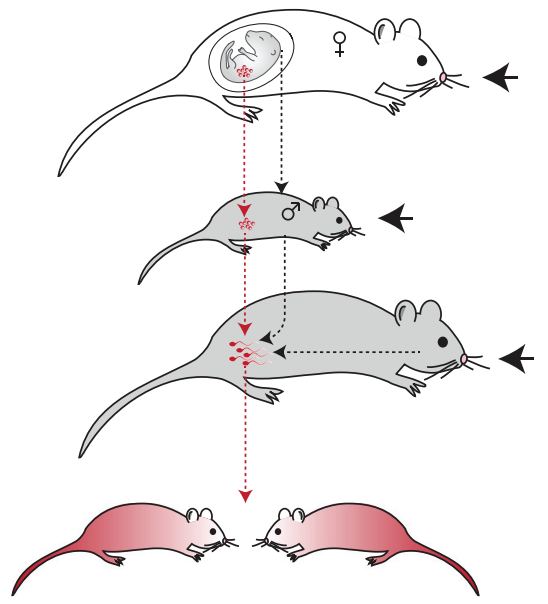

In utero exposure

Juvenile exposure

Adult exposure

Affected offspring

Figure 1

Paternal programming can result from environmental stressors experienced at various life stages in males. Nutritional stress experienced (top) in utero via altered maternal diet, (middle) pre-adolescence and (bottom) at reproductive age, have all been shown to propagate paternal effects to offspring. Developing germ cells (red) may be affected by in utero or prepubescent exposures and carry a memory of these exposures into adulthood (red arrows); alternatively, mature germ cells may be affected by the altered physiology of the exposed male in adulthood (black arrows).

male mice can propagate obesogenic and diabetogenic phenotypes through F1 and into (with incomplete penetrance) F2 offspring (Fullston et al. 2013). More robust multigenerational programming by paternal HFD has also recently been reported in rats, where two generations of offspring had reduced birthweight and impaired glucose tolerance; interestingly, the female F1 and F2 offspring of HFD sires were also resistant to diet-induced obesity (de Castro Barbosa et al. 2016). Mice that program impaired glucose tolerance and insulin sensitivity in their offspring after low-dose streptozotocin treatment appear to program in turn the same prediabetic phenotype in a succeeding generation of males (Wei et al. 2014). In these studies, it is likely that the affected F2 have themselves been subject to paternal programming by the affected F1 (i.e. serial programming); it is not possible to distinguish whether they are also displaying an inherited memory of ancestral exposure (Fig. 2).

A recent study from our own laboratory indicates that inheritance of paternally programmed metabolic effects does indeed occur (Cropley et al. 2016). Using a mouse model of natural-onset obesity, we found that paternal obesity and prediabetes induce a latent predisposition to hepatic insulin resistance in male offspring, which is unmasked when they are challenged with a Western-style diet. We exploited this latency to investigate inheritance. By breeding control-fed, metabolically normal F1 males, we found transmission of the metabolic phenotype to F2 with complete penetrance, indicating that the programmed phenotype was truly inherited from the grandfather.

That the legacy of a father's nutritional exposures can be transmitted not only to immediate offspring but also to subsequent generations has significant implications for public health over the long term. It also prompts the obvious question of mechanism. Although behavioral or social factors, or transfer of commensal microbiota, are all potential mediators, many of the animal models described here have employed study designs that preclude such mechanisms (e.g. males are removed from the dam after mating or conception is achieved in vitro). Paternal programming and its inheritance thus appear epigenetic, and the male lineage transmission observed in these
Serial programming

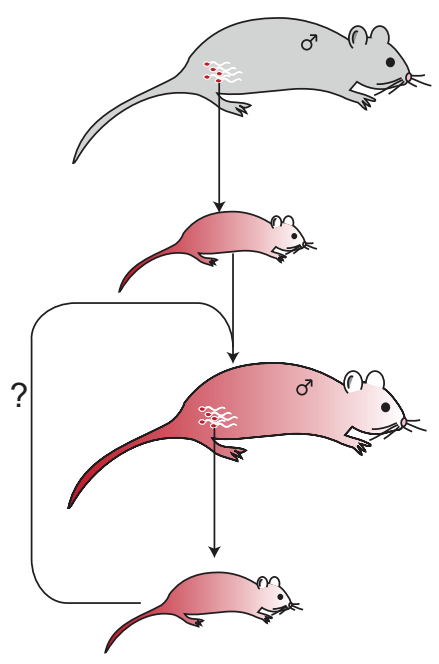

FO

F1

F1 adult

http://jme.endocrinology-journals.org DOI: 10.1530/JME-16-0236

\section{Epigenetic inheritance}

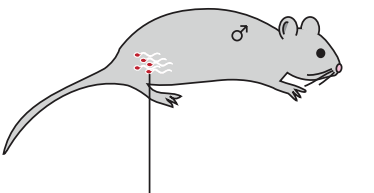

Figure 2

Propagation of paternal effects to subsequent generations. If the induced phenotype in F1 is similar or the same as the inducing stressor, the F1 phenotype can in turn program F2 phenotype: this process is known as 'serial programming' (left). This cycle could theoretically continue to propagate programming throughout many generations, but in practice, the number of affected generations probably depends upon the strength of the induced phenotype. Epigenetic inheritance (right) is independent of the induced phenotype as the programmed phenotype is inherited via the germ line; it allows for propagation of latent phenotypes or phenotypes that are dissimilar to the inducing stressor. Epigenetic inheritance and serial programming are difficult to distinguish, and probably occur together in many cases.
F2 
models thus implies that some factor in the sperm (other than the DNA sequence) is capable of transmitting information about paternal health to the next generation.

\section{More than the sum of his DNA: candidate mechanisms for paternal metabolic programming}

Heritable information has long been accepted to be carried by chromosomes, and the discovery of DNA in chromosomes led to the paradigm that all heredity stems from the stable transmission of DNA sequence through the germline. However, chromosomes contain material that is distinct from DNA yet transmitted with it, and thus has the potential to carry heritable information alongside the DNA. This material, the 'epigenome', is a complex assortment of proteins and chemical modifications that are associated with DNA and control its transcription. The molecular components of the mammalian epigenome include cytosine (DNA) methylation, histones and their modifications and the proteins that are recruited by histone modifications. The epigenome also comprises soluble factors, such as regulatory RNAs (Mercer \& Mattick 2013) that can determine or influence the action of other epigenetic modifications; this may be particularly relevant to mammalian sperm with their enormously complex assortment of non-coding RNA cargo (Schuster et al. 2016).

Alteration to the sperm epigenome is an intuitive candidate mechanism by which paternal programming might be mediated. By necessity, the epigenome is interposed between the genome and the environment, as it mediates the function of the genetic code: epigenetic modifications allow a single invariant genome to create many different phenotypes by responding to environmental cues (be they intrinsic or extrinsic). Although somatic epigenetic states are generally stable, germline epigenetic states are generally unstable, so may be more susceptible to environmental influence. If a change in the environmental conditions of developing or maturing sperm perturbs the sperm epigenome, this could lead to transmission of, or establishment of, variant epigenetic states in the next generation. The epigenome may thus provide a useful mechanism of phenotypic response to environmental stressors, that can readily be reversed when such stressors revert or change (Skinner 2011, Cropley et al. 2012).

There is now considerable evidence that environmental perturbations can be associated with altered epigenetic marks in sperm. Here, we summarize the current evidence implicating each of the main types of epigenetic molecules - cytosine methylation, chromatin proteins and regulatory RNAs - in paternal metabolic programming.

\section{Cytosine methylation}

DNA methylation is the best-characterized epigenetic modification. It is an intuitive candidate for transmissible epigenetic modification as it is stable, known to be heritable through cell division and is also retained during sperm maturation, when other epigenetic marks are largely removed.

Reports of changes to DNA methylation in somatic tissues of paternally programmed offspring are numerous, perhaps at least partly because DNA methylation is easy to assess experimentally. However, the biological significance of these changes can be difficult to interpret, as changes are often widespread throughout the genome, small in magnitude and affect a variety of genes; genes potentially relevant to the induced phenotype are generally present, if not prominent. For example, in mice, the livers of offspring of protein-restricted sires exhibit methylation changes at hundreds of loci, including within regulatory regions of Ppara, an important regulator of liver lipid metabolism (Carone et al. 2010). In humans, umbilical cord blood from neonates born to obese fathers harbors small methylation changes at imprinted genes implicated in fetal growth (Soubry et al. 2015).

Studies that have examined methylation in sperm of metabolically compromised founding sires (Martinez et al. 2014, Radford et al. 2014, Wei et al. 2014, de Castro Barbosa et al. 2016) have found similarly widespread, modest changes to DNA methylation patterns. Several studies have assessed methylation defects in both sperm of the founding sires and somatic tissue from the offspring. Some of these report no overlap (Carone et al. 2010, de Castro Barbosa et al. 2016), whereas others report commonalities of very modest changes (Martinez et al. 2014, Wei et al. 2014). But DNA methylation changes that are small in magnitude are necessarily mosaic. Thus, in haploid sperm, mosaic methylation changes occur only in the respective proportion of sperm, which is incompatible with methylation underlying the very high penetrance of programming that is generally observed (Rando \& Simmons 2015). Further, recent findings indicate that diet has little effect on broad methylation patterns in sperm, with the vast majority of methylation variation being due to genetic or sporadic variation (Shea et al. 2015). Taken together with the fact that most functional genomic elements are extensively demethylated after fertilization (Wang et al. 2014), it seems unlikely that aberrations in

Published by Bioscientifica Ltd 
cytosine methylation patterns are responsible for the transmission of programming from father to child.

It is possible however that methylation changes are a surrogate marker of alterations in epigenetic state mediated by another heritable molecular factor. This scenario would still allow a role for cytosine methylation changes in the development of metabolic phenotypes in offspring. Methylation biomarkers could identify both exposed individuals who may pass on disease risk and 'at-risk' programmed individuals. Further study into the informative power of such biomarkers may also prove to be valuable in further understanding mechanism when combined with other approaches.

\section{Chromatin alterations}

Epigenetic gene regulation fundamentally involves changes in chromatin structure: chromatin modifications are the only epigenetic modifications both necessary and sufficient for defining epigenetic states. But whether chromatin states can be carried through the germline is unclear. A major conceptual hurdle to this idea has been that the composition of chromatin in sperm is very different from that in the soma. In somatic cells, chromatin structure is associated with post-translational modifications to histones, which recruit proteins that define either an open or compacted chromatin configuration. But in sperm, chromatin is universally heavily compacted, and this is facilitated by the replacement of nucleosomes with smaller, heavily alkaline protamines. However, some nucleosomes are retained at promoters of developmentally important genes, and these nucleosomes contain post-translationally modified histones. It was recently shown using Xenopus that these retained histone modifications are important for regulating proper gene expression in the early embryo (Teperek et al. 2016).

Evidence for the involvement of chromatin alterations in paternal programming is very limited but compelling. Metabolic programming of Drosophila offspring by high-sugar feeding of fathers is dependent upon the histone methyltransferase $\mathrm{Su}(\mathrm{var}) 3-9$ and polycomb chromatin modifiers in both offspring and fathers themselves, and genes regulated by these modifiers exhibit altered expression in the paternal germline (Ost et al. 2014). Studies in vertebrate systems are lacking, and the potential involvement of heritable chromatin alterations in paternal programming in mammals remains an open question. Regardless of the heritability of chromatin states, the mechanisms that establish them in the germline and early embryo are not clearly defined; however, these mechanisms almost certainly involve the actions of non-coding RNA.

\section{Small non-coding RNA}

Sperm from most species are largely devoid of abundant ribosomal RNAs, but carry a rich payload of other RNAs, in particular small non-coding RNAs (sncRNA). sncRNA are regulatory RNAs that regulate the output of the genome in a number of ways, affecting transcription, splicing, translation and RNA modifications (Ghildiyal \& Zamore 2009, Morris \& Mattick 2014). The mammalian germline expresses microRNA, piwi-interacting RNA and endogenous small interfering RNA among others; many of these sncRNAs appear essential for germ cell development and germline integrity (Banisch et al. 2012).

Given sperm are transcriptionally inert, it was long thought that RNA present in sperm was merely residual, but it is now clear that sperm acquire their unique and complex cargo of sncRNAs after they leave the testes. Maturing sperm undergo an extensive reorganization of sncRNA content in the epididymal tract, epitomized by both gain and loss of hundreds of miRNAs (Nixon et al. 2015). This RNA remodeling probably occurs via interaction with RNA-rich extracellular vesicles shed from the epididymal epithelium (epididymosomes) (Belleannee et al. 2013, Reilly et al. 2016, Sharma et al. 2016). Epididymosome-mediated transfer of sncRNA to maturing sperm provides a way in which somatic cells might pass a signal of environmental exposures to the germline and potentially to offspring (Eaton et al. 2015). Available evidence indicates that sperm RNA is delivered to the oocyte along with the DNA (Ostermeier et al.2004), and work in the model worm $C$. elegans indicates that sperm-derived RNA accounts for a substantial proportion of the total RNA pool in the zygote (Stoeckius et al. 2014).

Invertebrate systems provide strong evidence for the involvement of sncRNA in transgenerational epigenetic inheritance, including in the inheritance of induced traits (Ashe et al. 2012, Buckley et al. 2012, Grentzinger et al. 2012, Rechavi et al. 2014). But sncRNAs are known to be pervasive in epigenetic regulation in invertebrates, whereas their role in mammalian epigenetics, particularly in the embryo, is less clear. Despite this uncertainty, multiple studies have implicated sncRNA in paternal programming effects, and these examples are not restricted to metabolism, suggesting a pervasive role for RNA in mediating paternal effects. Changes to sperm sncRNA composition have been reported in a range of induced traits (Wagner et al. 2008,

Published by Bioscientifica Ltd 
Gapp et al. 2014, Rodgers et al. 2015), including paternal metabolic compromise (Chen et al. 2016, Cropley et al. 2016, de Castro Barbosa et al. 2016, Sharma et al. 2016).

Like studies of DNA methylation in paternal metabolic programming, studies of the well-characterized microRNAs have yielded results idiosyncratic to the model system. However, several recent studies have suggested commonalities, and perhaps even a causal role for another abundant sncRNA species in sperm, tRNA fragments (tRFs). Both dietary protein restriction (Sharma et al. 2016) and HFD feeding (Chen et al. 2016) of fathers affect sperm tRF composition; in fact, tRFs appear more sensitive to these dietary interventions than other sperm sncRNA such as microRNA. Importantly, injection of sperm tRFs from HFD males into control zygotes was able to recapitulate the metabolic disorder induced in the HFD offspring, implying a causal link (Chen et al. 2016). Our own studies have implicated tRFs as mediators of the inheritance of the paternally-induced metabolic phenotype: we found perturbations to the same dietresponsive tRFs in the sperm of the male offspring of obese males. Such changes could not have been induced by exposure to obesity as in our model, the F1 progeny are unaffected when they are maintained on a healthy diet. Taken together with the observation that sperm tRFs appear sensitive to two opposing dietary stressors, this suggests that tRFs may represent a conserved mechanism for the passage of environmentally acquired phenotypes across generations.
Small RNAs such as tRFs delivered to sperm during their maturation are unlikely to have a function in the sperm itself; rather, it is likely that they function in the very early embryo (Fig. 3). Sperm sncRNA has been reported to induce transcriptional changes in the early embryo when injected into zygotes (Chen et al. 2016, Sharma et al. 2016), but whether these are direct or indirect transcriptional effects is unknown. Available evidence indicates that tRFs, like miRNA, reside predominantly in the cytoplasm (Garcia-Silva et al. 2012) where they can associate with polyribosomes and affect translation (Sobala \& Hutvagner 2013, Kumar et al. 2014). It may be that the transcriptional changes within embryos in response to sperm sncRNA are mediated by post-transcriptional mechanisms (Cropley et al. 2016).

\section{Is paternal programming adaptive?}

Paternal programming effects have been documented in both invertebrate and vertebrate species; available evidence points to heritability mechanisms involving non-coding RNA that may also be conserved. This begs the question of whether paternal programming holds some unique evolutionary significance. It has been proposed that the ability to respond to and transmit information about environmental changes to offspring has adaptive advantages (Feinberg \& Irizarry 2010, Hanson \& Gluckman 2014). In terms of paternal obesity, such a scenario may appear to be maladaptive. But widespread

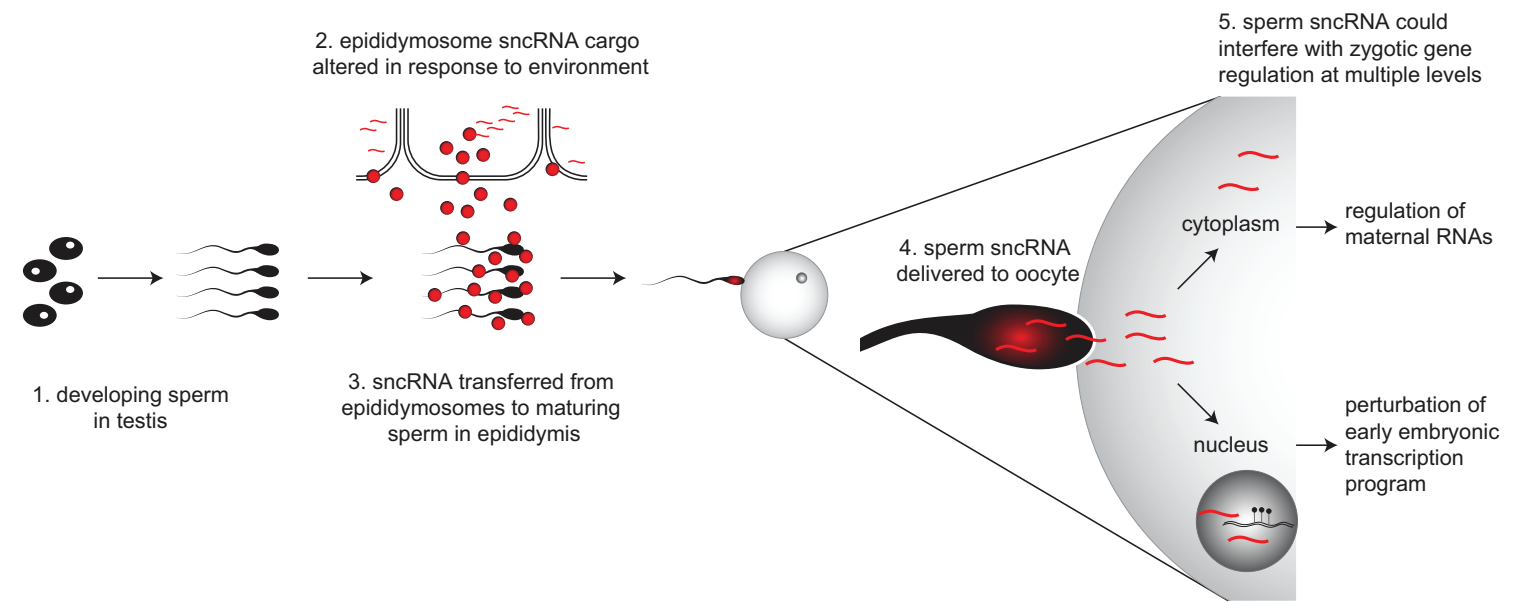

Figure 3

Model for the involvement of small non-coding RNA in paternal programming. Small RNA content of sperm may be altered by environmental conditions either during sperm development (1) or during maturation in the epididymis via interactions with RNA-rich epididymosomes (2, 3). Sperm deliver small RNAs to the oocyte upon fertilization (4), where they may affect early embryonic gene expression in a variety of ways (5). The small RNAs most abundant in sperm, miRNAs and tRFs are known as post-transcriptional regulators: their targets may be maternal RNAs, or, if they persist beyond the maternal-zygotic transition, embryonic transcripts. Sperm small RNAs may also find their way to the nucleus to perturb the early embryonic transcriptional program. 
obesity is a very modern phenomenon: presumably, the machinery underlying such responses has evolved in response to historical stressors for which a response might be adaptive, such as intermittent food shortages or climate changes. If these responses are epigenetic in nature this provides a way in which populations can revert to former phenotypes if environmental changes do not persist (Cropley et al. 2012). For example, paternally programmed RNA responses in the worm C. elegans are lost unless there is multigenerational exposure to the inducing stimulus (Houri-Ze'evi et al. 2016).

The paternal programming examples described in this review represent findings from transient exposures, followed for only a few generations. But what might be the consequences for humans exposed to stressors such as overnutrition for many generations? Studies in invertebrates may provide some insight. In a unique experiment performed with the caterpillar Plutella xylostella, multigenerational exposure to an obesogenic diet progressively led to a population of animals which, by the eighth generation of continuous exposure, had acquired the ability to eat excess carbohydrate without laying it down as fat; in other words, the population had become immune to the obesogenic effects of the diet (Warbrick-Smith et al. 2006). Selection acting on the reduced fitness of obese animals undoubtedly underpins this observation, and although in an outbred species such selection may be acting on genetic variants, epigenetic variants can also be selected for. We have previously shown (in mice) that a purely epigenetic trait induced by a dietary change can rapidly pervade a population when the dietary stress is sustained and coupled with selection for the induced trait (Cropley et al. 2012). Taken together with the potential for paternal effects to be heritable, these data raise the alternative possibility that acquired traits could become fixed in a population over time if they conferred a selective advantage. It is therefore plausible that humans could eventually become immune to the metabolic effects of parental overnutrition and its consequences if it were sustained over many generations.

\section{Conclusions and perspectives}

The idea that fathers contribute only their haploid genome to their offspring has been challenged by the many reports of paternal epigenetic programming. In terms of metabolism, the short-term consequences appear to be maladaptive: offspring of metabolically compromised fathers are themselves programmed to be metabolically compromised. Under the presence of persistent metabolic challenge, such as the intergenerational cycle of obesity of today's era, the long-term consequences are difficult to predict, but might potentially be beneficial at a population level. Nevertheless, paternal programming of metabolism highlights the need to focus on the health of both parents to achieve the most beneficial outcomes for children and future generations.

\section{Declaration of interest}

The authors declare that there is no conflict of interest that could be perceived as prejudicing the impartiality of this review.

\section{Funding}

This work was supported by the Australian Research Council (FT120100097 and DE120100723)

\section{References}

Abel E 2004 Paternal contribution to fetal alcohol syndrome. Addiction Biology 9 127-133; discussion 135-126. (doi:10.1080/1355621041000 1716980)

Anderson LM, Riffle L, Wilson R, Travlos GS, Lubomirski MS \& Alvord WG 2006 Preconceptional fasting of fathers alters serum glucose in offspring of mice. Nutrition 22 327-331. (doi:10.1016/j. nut.2005.09.006)

Ashe A, Sapetschnig A, Weick EM, Mitchell J, Bagijn MP, Cording AC, Doebley AL, Goldstein LD, Lehrbach NJ, Le Pen J, et al. 2012 piRNAs can trigger a multigenerational epigenetic memory in the germline of C. elegans. Cell 150 88-99. (doi:10.1016/j.cell.2012.06.018)

Banisch TU, Goudarzi M \& Raz E 2012 Small RNAs in germ cell development. Current Topics in Developmental Biology 99 79-113. (doi:10.1016/b978-0-12-387038-4.00004-5)

Barker DJ \& Osmond C 1986 Infant mortality, childhood nutrition, and ischaemic heart disease in England and Wales. Lancet 1 1077-1081. (doi:10.1016/S0140-6736(86)91340-1)

Barker DJ, Winter PD, Osmond C, Margetts B \& Simmonds SJ 1989 Weight in infancy and death from ischaemic heart disease. Lancet 2 577-580. (doi:10.1016/S0140-6736(89)90710-1)

Barouki R, Gluckman PD, Grandjean P, Hanson M \& Heindel JJ 2012 Developmental origins of non-communicable disease: implications for research and public health. Environmental Health 1142. (doi:10.1186/1476-069X-11-42)

Belleannee C, Calvo E, Caballero J \& Sullivan R 2013 Epididymosomes convey different repertoires of microRNAs throughout the bovine epididymis. Biology of Reproduction 89 30. (doi:10.1095/ biolreprod.113.110486)

Buchan JC, Alberts SC, Silk JB \& Altmann J 2003 True paternal care in a multi-male primate society. Nature 425 179-181. (doi:10.1038/ nature01866)

Buckley BA, Burkhart KB, Gu SG, Spracklin G, Kershner A, Fritz H, Kimble J, Fire A \& Kennedy S 2012 A nuclear Argonaute promotes multigenerational epigenetic inheritance and germline immortality. Nature 489 447-451. (doi:10.1038/nature11352)

Bygren LO, Kaati G \& Edvinsson S 2001 Longevity determined by paternal ancestors' nutrition during their slow growth period. Acta Biotheoretica 49 53-59. (doi:10.1023/A:1010241825519)

Carone BR, Fauquier L, Habib N, Shea JM, Hart CE, Li R, Bock C, Li C, Gu H, Zamore PD, et al. 2010 Paternally induced transgenerational environmental reprogramming of metabolic gene expression in mammals. Cell 143 1084-1096. (doi:10.1016/j. cell.2010.12.008)

Published by Bioscientifica Ltd. 
Chen YP, Xiao XM, Li J, Reichetzeder C, Wang ZN \& Hocher B 2012 Paternal body mass index (BMI) is associated with offspring intrauterine growth in a gender dependent manner. PLOS ONE 7 e36329. (doi:10.1371/journal.pone.0036329)

Chen Q, Yan M, Cao Z, Li X, Zhang Y, Shi J, Feng GH, Peng H, Zhang X, Zhang Y, et al. 2016 Sperm tsRNAs contribute to intergenerational inheritance of an acquired metabolic disorder. Science 351 397-400. (doi:10.1126/science.aad7977)

Cooper R, Hypponen E, Berry D \& Power C 2010 Associations between parental and offspring adiposity up to midlife: the contribution of adult lifestyle factors in the 1958 British Birth Cohort Study. American Journal of Clinical Nutrition 92 946-953. (doi:10.3945/ ajcn.2010.29477)

Crean AJ \& Bonduriansky R 2014 What is a paternal effect? Trends in Ecology and Evolution 29 554-559. (doi:10.1016/j.tree.2014.07.009)

Cropley JE, Dang TH, Martin DI \& Suter CM 2012 The penetrance of an epigenetic trait in mice is progressively yet reversibly increased by selection and environment. Proceedings: Biological Sciences $\mathbf{2 7 9}$ 2347-2353. (doi:10.1098/rspb.2011.2646)

Cropley JE, Eaton SA, Aiken A, Young PE, Giannoulatou E, Ho JW, Buckland ME, Keam SP, Hutvagner G, Humphreys DT, et al. 2016 Male-lineage transmission of an acquired metabolic phenotype induced by grand-paternal obesity. Molecular Metabolism 5 699-708. (doi:10.1016/j.molmet.2016.06.008)

de Castro Barbosa T, Ingerslev LR, Alm PS, Versteyhe S, Massart J, Rasmussen M, Donkin I, Sjogren R, Mudry JM, Vetterli L, et al. 2016 High-fat diet reprograms the epigenome of rat spermatozoa and transgenerationally affects metabolism of the offspring. Molecular Metabolism 5 184-197. (doi:10.1016/j.molmet.2015.12.002)

Dias BG \& Ressler KJ 2014 Parental olfactory experience influences behavior and neural structure in subsequent generations. Nature Neuroscience 17 89-96. (doi:10.1038/nn.3594)

Dunn GA \& Bale TL 2009 Maternal high-fat diet promotes body length increases and insulin insensitivity in second-generation mice. Endocrinology 150 4999-5009. (doi:10.1210/en.2009-0500)

Eaton SA, Jayasooriah N, Buckland ME, Martin DI, Cropley JE \& Suter CM 2015 Roll over Weismann: extracellular vesicles in the transgenerational transmission of environmental effects. Epigenomics 7 1165-1171. (doi:10.2217/epi.15.58)

Eggert A, Reinking M \& Muller JK 1998 Parental care improves offspring survival and growth in burying beetles. Animal Behaviour 55 97-107. (doi:10.1006/anbe.1997.0588)

Eriksen W, Sundet JM \& Tambs K 2013 Paternal age at birth and the risk of obesity in young adulthood: a register-based birth cohort study of norwegian males. American Journal of Human Biology 25 29-34. (doi:10.1002/ajhb.22333)

Farah Naquiah MZ, James RJ, Suratman S, Lee LS, Mohd Hafidz MI, Salleh MZ \& Teh LK 2016 Transgenerational effects of paternal heroin addiction on anxiety and aggression behavior in male offspring. Behavioral and Brain Functions 12 23. (doi:10.1186/s12993016-0107-y)

Feinberg AP \& Irizarry RA 2010 Evolution in health and medicine Sackler colloquium: stochastic epigenetic variation as a driving force of development, evolutionary adaptation, and disease. PNAS $\mathbf{1 0 7}$ (Supplement 1) 1757-1764. (doi:10.1073/pnas.0906183107)

Figueroa-Colon R, Arani RB, Goran MI \& Weinsier RL 2000 Paternal body fat is a longitudinal predictor of changes in body fat in premenarcheal girls. American Journal of Clinical Nutrition $\mathbf{7 1}$ 829-834.

Flegal KM, Carroll MD, Ogden CL \& Curtin LR 2010 Prevalence and trends in obesity among US adults, 1999-2008. JAMA 303 235-241. (doi:10.1001/jama.2009.2014)

Fontelles CC, Guido LN, Rosim MP, Andrade Fde O, Jin L, Inchauspe J, Pires VC, de Castro IA, Hilakivi-Clarke L, de Assis S, et al. 2016 Paternal programming of breast cancer risk in daughters in a rat model: opposing effects of animal- and plant-based high-fat diets. Breast Cancer Research 18 71. (doi:10.1186/s13058-016-0729-x)

Fullston T, Teague EMCO, Palmer NO, DeBlasio MJ, Mitchell M, Corbett M, Owens JA \& Lane M 2013 Paternal obesity initiates metabolic disturbances in two generations of mice with incomplete penetrance to the F2 generation and alters the transcriptional profile of testis and sperm microRNA content. FASEB Journal 27 4226-4243. (doi:10.1096/fj.12-224048)

Gapp K, Jawaid A, Sarkies P, Bohacek J, Pelczar P, Prados J, Farinelli L, Miska E \& Mansuy IM 2014 Implication of sperm RNAs in transgenerational inheritance of the effects of early trauma in mice. Nature Neuroscience 17 667-669. (doi:10.1038/nn.3695)

Garcia-Silva MR, Cabrera-Cabrera F, Guida MC \& Cayota A 2012 Hints of tRNA-derived small RNAs role in RNA silencing mechanisms. Genes 3 603-614. (doi:10.3390/genes3040603)

Ghildiyal M \& Zamore PD 2009 Small silencing RNAs: an expanding universe. Nature Reviews Genetics 10 94-108. (doi:10.1038/nrg2504)

Goldner MG \& Spergel G 1972 On the transmission of alloxan diabetes and other diabetogenic influences. Advances in Metabolic Disorders 60 57-72. (doi:10.1016/b978-0-12-027306-5.50007-3)

Grentzinger T, Armenise C, Brun C, Mugat B, Serrano V, Pelisson A \& Chambeyron S 2012 piRNA-mediated transgenerational inheritance of an acquired trait. Genome Research 22 1877-1888. (doi:10.1101/ gr.136614.111)

Hanson M 2015 The birth and future health of DOHaD. Journal of Developmental Origins of Health and Disease 6 434-437. (doi:10.1017/ S2040174415001129)

Hanson MA \& Gluckman PD 2014 Early developmental conditioning of later health and disease: physiology or pathophysiology? Physiological Reviews 94 1027-1076. (doi:10.1152/ physrev.00029.2013)

Heindel JJ, Balbus J, Birnbaum L, Brune-Drisse MN, Grandjean P, Gray K, Landrigan PJ, Sly PD, Suk W, Cory Slechta D, et al. 2015 Developmental origins of health and disease: integrating environmental influences. Endocrinology 156 3416-3421. (doi:10.1210/EN.2015-1394)

Houri-Ze'evi L, Korem Y, Sheftel H, Faigenbloom L, Toker IA, Dagan Y, Awad L, Degani L, Alon U \& Rechavi O 2016 A tunable mechanism determines the duration of the transgenerational small RNA inheritance in C. elegans. Cell 165 88-99. (doi:10.1016/j. cell.2016.02.057)

Jimenez-Chillaron JC, Isganaitis E, Charalambous M, Gesta S, Pentinat-Pelegrin T, Faucette RR, Otis JP, Chow A, Diaz R, Ferguson-Smith A, et al. 2009 Intergenerational transmission of glucose intolerance and obesity by in utero undernutrition in mice. Diabetes 58 460-468. (doi:10.2337/db08-0490)

Kaati G, Bygren LO \& Edvinsson S 2002 Cardiovascular and diabetes mortality determined by nutrition during parents' and grandparents' slow growth period. European Journal of Human Genetics 10 682-688. (doi:10.1038/sj.ejhg.5200859)

Kumar P, Anaya J, Mudunuri SB \& Dutta A 2014 Meta-analysis of tRNA derived RNA fragments reveals that they are evolutionarily conserved and associate with AGO proteins to recognize specific RNA targets. BMC Biology 12 78. (doi:10.1186/s12915-014-0078-0)

Mamun AA \& Finlay JE 2015 Shifting of undernutrition to overnutrition and its determinants among women of reproductive ages in the 36 low to medium income countries. Obesity Research and Clinical Practice 9 75-86. (doi:10.1016/j. orcp.2014.03.001)

Martinez D, Pentinat T, Ribo S, Daviaud C, Bloks VW, Cebria J, Villalmanzo N, Kalko SG, Ramon-Krauel M, Diaz R, et al. 2014 In utero undernutrition in male mice programs liver lipid metabolism in the second-generation offspring involving altered Lxra DNA methylation. Cell Metabolism 19 941-951. (doi:10.1016/j. cmet.2014.03.026) http://jme.endocrinology-journals.org

DOI: 10.1530/JME-16-0236
() 2017 Society for Endocrinology Printed in Great Britain 
Mercer TR \& Mattick JS 2013 Structure and function of long noncoding RNAs in epigenetic regulation. Nature Structural and Molecular Biology 20 300-307. (doi:10.1038/nsmb.2480)

Morris KV \& Mattick JS 2014 The rise of regulatory RNA. Nature Reviews Genetics 15 423-437. (doi:10.1038/nrg3722)

Ng S-F, Lin R, Laybutt D, Barres R, Owens J \& Morris M 2010 Chronic high-fat diet in fathers programs $\beta$-cell dysfunction in female rat offspring. Nature 467 963-969. (doi:10.1038/nature09491)

Nixon B, Stanger SJ, Mihalas BP, Reilly JN, Anderson AL, Tyagi S, Holt JE \& McLaughlin EA 2015 The microRNA signature of mouse spermatozoa is substantially modified during epididymal maturation. Biology of Reproduction 93 91. (doi:10.1095/biolreprod.115.132209)

Okamoto K 1965 Apparent transmission of factors to offspring by animals with experimental diabetes. In On the Nature and Treatment of Diabetes. Eds BS Liebell \& GA Wrenshall. Amsterdam, Netherlands: Excerpta Medica Foundation.

Ost A, Lempradl A, Casas E, Weigert M, Tiko T, Deniz M, Pantano L, Boenisch U, Itskov PM, Stoeckius M, et al. 2014 Paternal diet defines offspring chromatin state and intergenerational obesity. Cell 159 1352-1364. (doi:10.1016/j.cell.2014.11.005)

Ostermeier GC, Miller D, Huntriss JD, Diamond MP \& Krawetz SA 2004 Reproductive biology: delivering spermatozoan RNA to the oocyte. Nature 429 154. (doi:10.1038/429154a)

Pembrey ME, Bygren LO, Kaati G, Edvinsson S, Northstone K, Sjostrom M \& Golding J 2006 Sex-specific, male-line transgenerational responses in humans. European Journal of Human Genetics $\mathbf{1 4}$ 159-166. (doi:10.1038/sj.ejhg.5201538)

Radford EJ, Ito M, Shi H, Corish JA, Yamazawa K, Isganaitis E, Seisenberger S, Hore TA, Reik W, Erkek S, et al. 2014 In utero effects. In utero undernourishment perturbs the adult sperm methylome and intergenerational metabolism. Science 3451255903. (doi:10.1126/science.1255903)

Rando OJ 2012 Daddy issues: paternal effects on phenotype. Cell 151 702-708. (doi:10.1016/j.cell.2012.10.020)

Rando OJ \& Simmons RA 2015 I'm eating for two: parental dietary effects on offspring metabolism. Cell 161 93-105. (doi:10.1016/j. cell.2015.02.021)

Rechavi O, Houri-Ze'evi L, Anava S, Goh WS, Kerk SY, Hannon GJ \& Hobert O 2014 Starvation-induced transgenerational inheritance of small RNAs in C. elegans. Cell 158 277-287. (doi:10.1016/j. cell.2014.06.020)

Reilly JN, McLaughlin EA, Stanger SJ, Anderson AL, Hutcheon K, Church K, Mihalas BP, Tyagi S, Holt JE, Eamens AL, et al. 2016 Characterisation of mouse epididymosomes reveals a complex profile of microRNAs and a potential mechanism for modification of the sperm epigenome. Scientific Reports 6 31794. (doi:10.1038/srep31794)

Rodgers AB, Morgan CP, Bronson SL, Revello S \& Bale TL 2013 Paternal stress exposure alters sperm microRNA content and reprograms offspring HPA stress axis regulation. Journal of Neuroscience $\mathbf{3 3}$ 9003-9012. (doi:10.1523/JNEUROSCI.0914-13.2013)

Rodgers AB, Morgan CP, Leu NA \& Bale TL 2015 Transgenerational epigenetic programming via sperm microRNA recapitulates effects of paternal stress. PNAS 112 13699-13704. (doi:10.1073/pnas.1508347112)

Savage T, Derraik JG, Miles HL, Mouat F, Hofman PL \& Cutfield WS 2014 Increasing paternal age at childbirth is associated with taller stature and less favourable lipid profiles in their children. Clinical Endocrinology 80 253-260. (doi:10.1111/cen.12276)

Schuster A, Tang C, Xie Y, Ortogero N, Yuan S \& Yan W 2016 SpermBase: a database for sperm-borne RNA contents. Biology of Reproduction 95 99. (doi:10.1095/biolreprod.116.142190)

Sharma U, Conine CC, Shea JM, Boskovic A, Derr AG, Bing XY, Belleannee C, Kucukural A, Serra RW, Sun F, et al. 2016 Biogenesis and function of tRNA fragments during sperm maturation and fertilization in mammals. Science 351 391-396. (doi:10.1126/ science.aad6780)

Shea JM, Serra RW, Carone BR, Shulha HP, Kucukural A, Ziller MJ, Vallaster MP, Gu H, Tapper AR, Gardner PD, et al. 2015 Genetic and epigenetic variation, but not diet, shape the sperm methylome. Developmental Cell 35 750-758. (doi:10.1016/j.devcel.2015.11.024)

Skinner MK 2011 Environmental epigenetic transgenerational inheritance and somatic epigenetic mitotic stability. Epigenetics 6 838-842. (doi:10.4161/epi.6.7.16537)

Sobala A \& Hutvagner G 2013 Small RNAs derived from the 5' end of tRNA can inhibit protein translation in human cells. RNA Biology $\mathbf{1 0}$ 553-563. (doi:10.4161/rna.24285)

Soubry A, Murphy SK, Wang F, Huang Z, Vidal AC, Fuemmeler BF, Kurtzberg J, Murtha A, Jirtle RL, Schildkraut JM, et al. 2015 Newborns of obese parents have altered DNA methylation patterns at imprinted genes. International Journal of Obesity 39 650-657. (doi:10.1038/ijo.2013.193)

Spergel G, Levy LJ \& Goldner MG 1971 Glucose intolerance in the progeny of rats treated with single subdiabetogenic dose of alloxan. Metabolism 20 401-413. (doi:10.1016/00260495(71)90102-8)

Stoeckius M, Grun D \& Rajewsky N 2014 Paternal RNA contributions in the Caenorhabditis elegans zygote. EMBO Journal 33 1740-1750. (doi:10.15252/embj.201488117)

Tarry-Adkins JL \& Ozanne SE 2016 Nutrition in early life and age-associated diseases. Ageing Research Reviews [in press]. (doi:10.1016/j.arr.2016.08.003)

Teperek M, Simeone A, Gaggioli V, Miyamoto K, Allen GE, Erkek S, Kwon T, Marcotte EM, Zegerman P, Bradshaw CR, et al. 2016 Sperm is epigenetically programmed to regulate gene transcription in embryos. Genome Research 26 1034-1046. (doi:10.1101/gr.201541.115)

Tyrrell JS, Yaghootkar H, Freathy RM, Hattersley AT \& Frayling TM 2013 Parental diabetes and birthweight in 236030 individuals in the UK biobank study. International Journal of Epidemiology 42 1714-1723. (doi:10.1093/ije/dyt220)

Vickers M 2014 Developmental programming and transgenerational transmission of obesity. Annals of Nutrition and Metabolism 64 26-34. (doi:10.1159/000360506)

Wagner KD, Wagner N, Ghanbarian H, Grandjean V, Gounon P, Cuzin F $\&$ Rassoulzadegan M 2008 RNA induction and inheritance of epigenetic cardiac hypertrophy in the mouse. Developmental Cell 14 962-969. (doi:10.1016/j.devcel.2008.03.009)

Wang L, Zhang J, Duan J, Gao X, Zhu W, Lu X, Yang L, Zhang J, Li G, Ci W, et al. 2014 Programming and inheritance of parental DNA methylomes in mammals. Cell 157 979-991. (doi:10.1016/j. cell.2014.04.017)

Warbrick-Smith J, Behmer ST, Lee KP, Raubenheimer D \& Simpson SJ 2006 Evolving resistance to obesity in an insect. PNAS 103 14045-14049. (doi:10.1073/pnas.0605225103)

Watkins AJ \& Sinclair KD 2014 Paternal low protein diet affects adult offspring cardiovascular and metabolic function in mice. American Journal of Physiology: Heart and Circulatory Physiology $\mathbf{3 0 6}$ H1444-H1452. (doi:10.1152/ajpheart.00981.2013)

Wei Y, Yang C-R, Wei Y-P, Zhao Z-A, Hou Y, Schatten H \& Sun Q-Y 2014 Paternally induced transgenerational inheritance of susceptibility to diabetes in mammals. PNAS 111 1873-1878. (doi:10.1073/ pnas.1321195111)

Whincup PH, Kaye SJ, Owen CG, Huxley R, Cook DG, Anazawa S, Barrett-Connor E, Bhargava SK, Birgisdottir BE, Carlsson S, et al. 2008 Birth weight and risk of type 2 diabetes: a systematic review. JAMA 300 2886-2897. (doi:10.1001/jama.2008.886)

Received in final form 23 November 2016

Accepted 5 January 2017

Accepted Preprint published online 18 January 2017

Published by Bioscientifica Ltd. http://jme.endocrinology-journals.org

DOI: 10.1530/JME-16-0236
() 2017 Society for Endocrinology Printed in Great Britain 